
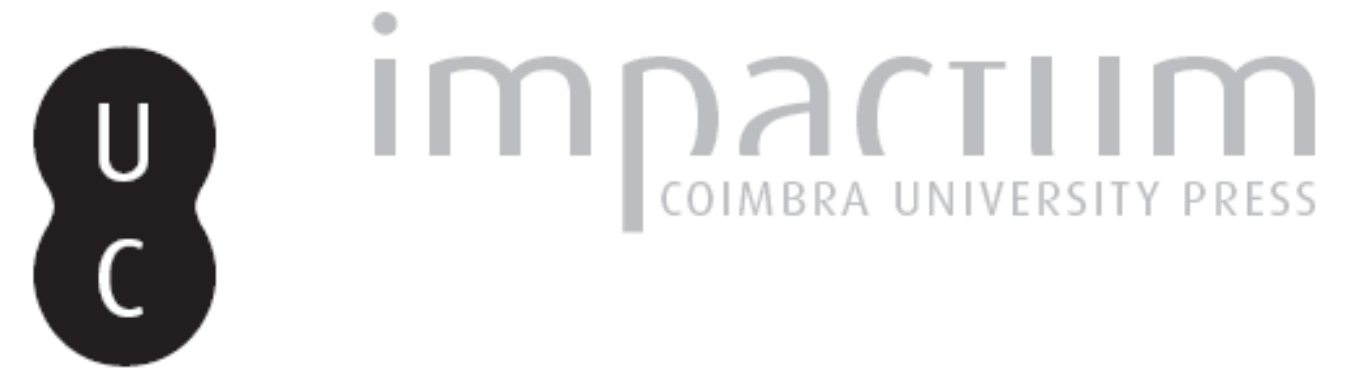

\title{
O "Ciclone" de fevereiro de 1941: análise histórico-geográfica dos seus efeitos no município de Coimbra
}

Autor(es): $\quad$ Nunes, Adélia; Pinho, João; Ganho, Nuno

Publicado por: $\begin{aligned} & \text { Faculdade de Letras da Universidade de Coimbra, Departamento de } \\ & \text { Geografia }\end{aligned}$

URL

persistente:

URI:http://hdl.handle.net/10316.2/30196

DOI: DOI:http://dx.doi.org/10.14195/0871-1623_31_5

Accessed : $\quad$ 26-Apr-2023 06:41:06

A navegação consulta e descarregamento dos títulos inseridos nas Bibliotecas Digitais UC Digitalis, UC Pombalina e UC Impactum, pressupõem a aceitação plena e sem reservas dos Termos e Condições de Uso destas Bibliotecas Digitais, disponíveis em https://digitalis.uc.pt/pt-pt/termos.

Conforme exposto nos referidos Termos e Condições de Uso, o descarregamento de títulos de acesso restrito requer uma licença válida de autorização devendo o utilizador aceder ao(s) documento(s) a partir de um endereço de IP da instituição detentora da supramencionada licença.

Ao utilizador é apenas permitido o descarregamento para uso pessoal, pelo que o emprego do(s) título(s) descarregado(s) para outro fim, designadamente comercial, carece de autorização do respetivo autor ou editor da obra.

Na medida em que todas as obras da UC Digitalis se encontram protegidas pelo Código do Direito de Autor e Direitos Conexos e demais legislação aplicável, toda a cópia, parcial ou total, deste documento, nos casos em que é legalmente admitida, deverá conter ou fazer-se acompanhar por este aviso. 


\title{
0 "Ciclone" de fevereiro de 1941: análise histórico-geográfica dos seus efeitos no município de Coimbra
}

\author{
Adélia Nunes \\ Departamento de Geografia e Centro de Estudos de Geografia e Ordenamento do Território (CEGOT). Faculdade de Letras da Universidade de Coimbra. \\ João Pinho \\ Investigador de História Local e Regional \\ Nuno Ganho \\ Departamento de Geografia e Centro de Estudos de Geografia e Ordenamento do Território (CEGOT). Faculdade de Letras da Universidade de Coimbra.
}

\section{Resumo:}

Os fortes ventos que assolaram o território português no dia 15 de Fevereiro de 1941 poderão ser considerados os mais violentos desde que há recolha de registos meteorológicos (finais do século XIX), causando um elevado número de vítimas humanas e avultados danos materiais. Com o presente trabalho pretende-se fazer uma análise às condições meteorológicas responsáveis pelos fortes ventos, cujas rajadas máximas atingiram no Porto $130 \mathrm{~km} / \mathrm{h}$, em Coimbra $133 \mathrm{~km} / \mathrm{h}$ e em Lisboa $127 \mathrm{~km} / \mathrm{h}$. Com recurso a jornais da época e a outras fontes estatístico-documentais, apresenta-se uma síntese dos principais efeitos deste temporal a nível nacional e aprofundam-se as suas consequências no município de Coimbra. Por último, problematiza-se a exposição e a vulnerabilidade à época e os potenciais efeitos da manifestação deste tipo de risco na atualidade.

Palavras-chave: Ventos fortes. Impactes. Vulnerabilidade. Coimbra. Portugal.

\section{Résumé:}

Le «Cyclone» de Février 1941: analyse historique et géographique de ses effets dans le municipe de Coimbra

Les vents forts qui ont dévasté le territoire portugais dans Février 15 de 1941, peut être considéré le plus violent puisqu'il ya d'enregistrements météorologiques (fin du XIXe siècle), causant un grand nombre de pertes en vies humaines et considérables dommages matériels. Le présent travail vise faire une analyse aux conditions météorologiques responsables pour les forts vents qui ont atteint rafales maximales de $130 \mathrm{~km} / \mathrm{h}$ dans le Porto, $133 \mathrm{~km} / \mathrm{h}$ dans Coimbra et $127 \mathrm{~km} / \mathrm{h}$ dans Lisboa. Avec l'utilisation de journaux et d'autres sources statistiques-documentaires on présente une synthèse des principaux effets de cette tempête au niveau national et leurs impactes sur le municipe de Coimbra seront encore. Finalement, se problématise l'exposition et la vulnérabilité à l'époque et les effets potentiels de la manifestation de ce type de risque aujourd'hui.

Mots-clés: Vents forts. Impactes. Vulnérabilité. Coimbra. Portugal.

\section{Abstract:}

The "Cyclone" of February 1941: Historical and geographical analysis of its effects in the municipality of Coimbra

The strong winds that devastated the Portuguese territory on $15^{\text {th }}$ February 1941 could be considered the most violent since there are collecting of weather records (late nineteenth century), causing a large number of human casualties and considerable property damages. The present work aims to carry out an analysis to weather conditions responsible for the strong winds, which reached peak gusts of $130 \mathrm{~km} / \mathrm{h}$ in Porto, $133 \mathrm{~km} / \mathrm{h}$ in Coimbra and in $127 \mathrm{~km} / \mathrm{h}$ in Lisboa. Based on newspapers and other statistical and time-documentary sources, a summary of the main effects of this windstorm are presented at national level and a deepen analysis of their impact will be presented to the municipality of Coimbra. Finally, the exposure and vulnerability to time and the potential effects of the manifestation of this type of risk today will be discussed.

Keywords: Strong winds. Impacts. Vulnerability. Coimbra. Portugal. 
Introdução

Os episódios de vento forte constituem um dos riscos meteorológicos mais característicos do nosso território, todavia são escassos os trabalhos científicos em que se abordam, quer as causas meteorológicas quer os respetivos danos provocados. Destacam-se, todavia, os realizados por Oliveira e Lopes (2007) e Lopes e Fragoso (2010). Entre esses fenómenos extremos encontram-se os fortes ventos que assolaram o território português no dia 15 de Fevereiro de 1941, os quais poderão ser considerados os mais violentos desde que há registos meteorológicos (finais do século XIX), pelo elevado número de perdas humanas (com o perecimento de várias dezenas de pessoas) e pelos avultados danos materiais causados.

A imprensa da época, O Século, o Diário de Notícias ou o Jornal de Notícias, divulgou, nos dias seguintes, os efeitos nefastos desta tempestade, que se fizeram sentir um pouco por todo o território peninsular, destacando no nosso país, além do elevado número de vítimas mortais, os milhares de árvores arrancadas, as inúmeras estradas intransitáveis, as casas destelhadas, as povoações isoladas, a rede elétrica destruída e as ligações telegráficas e telefónicas interrompidas. Os prejuízos foram, então, avaliados em cerca de 1 milhão de contos. Pese embora a magnitude alcançada por este temporal, surpreende num primeiro momento a escassez de referências e estudos que o analisem (RuBıo, 2001).

Com o presente trabalho pretende-se fazer uma análise às causas sinópticas responsáveis pelos fortes ventos, cujas rajadas máximas atingiram, em 15 de Fevereiro, no Porto $130 \mathrm{~km} / \mathrm{h}^{1}$, em Coimbra $133 \mathrm{~km} / \mathrm{h}$, em Penhas Douradas $148 \mathrm{~km} / \mathrm{h}$, em Lisboa $127 \mathrm{~km} / \mathrm{h}$ e em Portimão/Tavira $150 \mathrm{~km} / \mathrm{h}$. Já os quantitativos de precipitação foram relativamente reduzidos, a oscilar entre os 7,8mm de Coimbra e os $16,5 \mathrm{~mm}$ de Lisboa.

Para além da análise das causas meteorológicas, pretende-se apresentar uma síntese dos principais efeitos deste temporal a nível nacional e analisar, com mais detalhe, os respetivos impactes no município de Coimbra. Por último, problematiza-se a exposição e vulnerabilidade à época e os potenciais efeitos da manifestação deste tipo de risco na atualidade.

\section{Materiais e métodos}

No que se refere à evolução da situação sinóptica à superfície $(\mathrm{nmm})$ e na média troposfera (geopotencial

Rajada máxima alcançada antes de avariar o anemómetro. a $500 \mathrm{hPa}$ ), as cartas sinópticas foram consultadas nos arquivos on-line de sites especializados (nomeadamente www.wetterzentrale.de e www.meteociel.fr), as quais foram obtidas por reanálises NCEP e NOAA-CR20, das $12 \mathrm{~h}$ UTC de 14 de Fevereiro, às 00h UTC de 16 de Fevereiro de 1941.

$\mathrm{Na}$ inventariação dos principais efeitos a nível nacional recorreu-se aos jornais da época com especial destaque para o Século, o Jornal de Notícias e o Diário de Notícias (Figura 1). Na relação dos prejuízos referentes ao município de Coimbra utilizaram-se os dados extraídos das "respostas aos inquéritos" mandados realizar pela Comissão Nacional de Auxilio às Vitimas do Ciclone, dependente do Ministério do Interior. Com a constituição desta comissão pretendia-se colher, por todo o país, informações junto das autoridades administrativas, ou eclesiásticas, e pessoas particulares, «relações circunstanciadas»:

a) Das famílias cujos chefes tivessem perecido na catástrofe, indicando o $\mathrm{n}^{\circ}$ de órfãos, idades e sexos...

b) Das famílias que viram a sua pequena moradia derrubada ou «inteiramente subvertidos os seus haveres constituídos por um único prédio rústico, sem possibilidades de os reconstituir (...) poderão desde já indicar qual o auxílio em materiais...»

c) Das famílias que perderam barcos, redes ou quaisquer outros instrumentos de trabalho que constituíssem a base exclusiva da sua pequena economia».

Esta informação encontra-se disponível no AHMCArquivo Histórico Municipal de Coimbra. Utilizaram-se, ainda, outros dados recolhidos no Instituto Nacional de Meteorologia, Instituto Geofísico da Universidade de Coimbra e Instituto Nacional de Estatística.

\section{Resultados}

\section{Causas sinópticas}

Os episódios de vento particularmente forte, como o que ocorreu em Portugal Continental (e metade Noroeste da Península Ibérica) no dia 15 de Fevereiro de 1941, ou se tratam de situações de carácter local, de dimensão espacial e temporal restrita, associadas a forte instabilidade vertical da troposfera e a consequentes células nebulosas de grande desenvolvimento vertical (caso de tornados ou de downbursts), ou se generalizam a um espaço mais vasto, durante várias horas, como foi o caso da situação em análise. Estas tempes- 

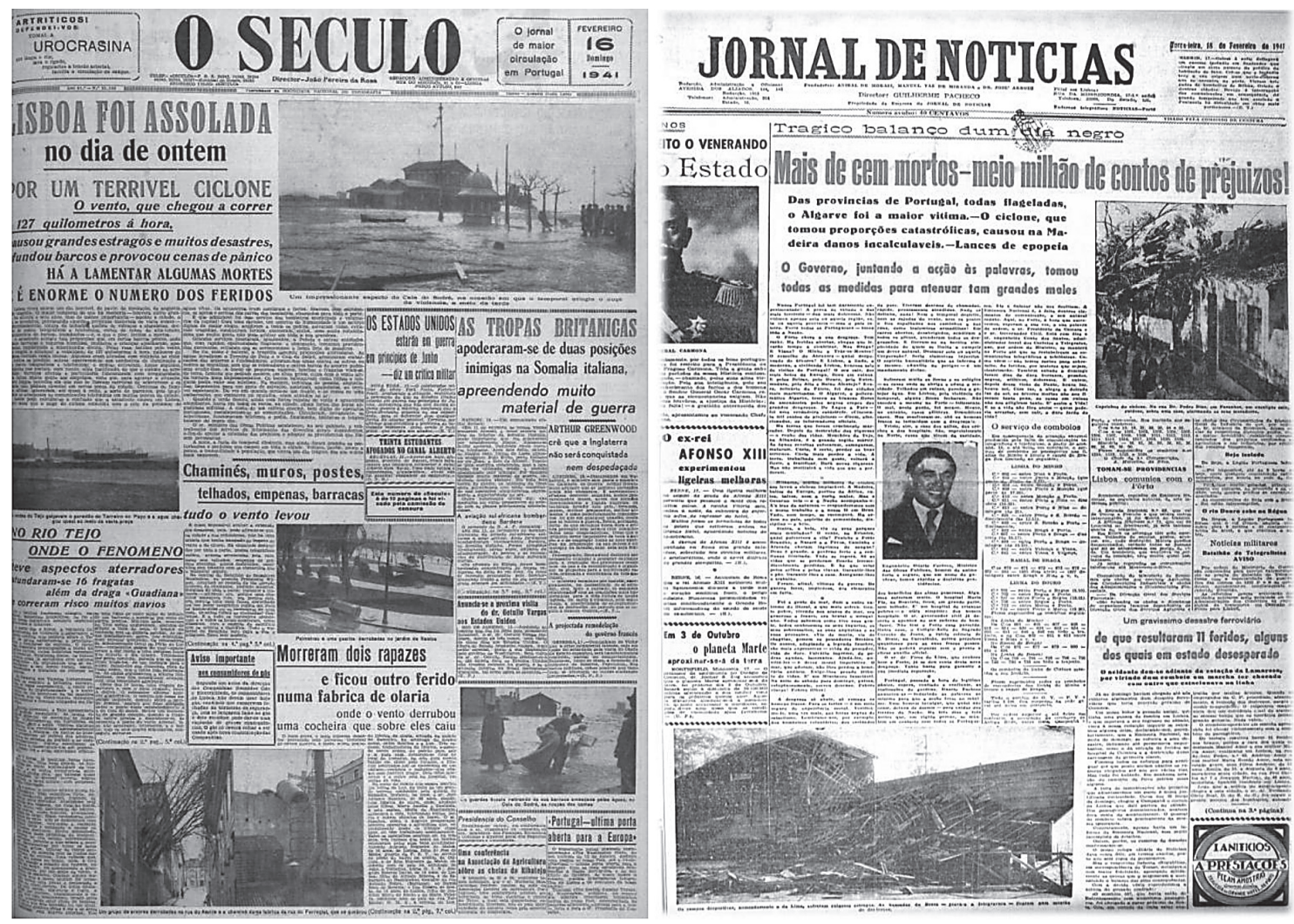

Figura 1

Os jornais como fontes privilegiadas na inventariação dos danos causados pelo Ciclone de 1941. O exemplo do Século, do dia seguinte, e do Jornal de Notícias, do dia 18 de Fevereiro.

tades de vento, de escala sinóptica, são normalmente determinadas por perturbações extratropicais, de carácter frontal ou de gota-fria com linhas de instabilidade, em ambos os casos com fortes gradientes barométricos e intensa actividade convectiva.

A evolução da situação sinóptica à superfície (nmm) e na média troposfera (geopotencial a $500 \mathrm{hPa}$ ), das $12 \mathrm{~h}$ UTC de 14 de Fevereiro, às 00h UTC de 16 de Fevereiro de 1941, permite analisar, com um rigor científico significativo, as causas subjacentes a este paroxismo climático-meteorológico de interesse histórico e consequências trágicas em Portugal.

Às 12h UTC do dia 14 de Fevereiro de 1941 (Fig. 2A) a cartografia sinóptica revela uma situação de alto índice zonal, com um índice da Oscilação Norte Atlântica $(\mathrm{NAO})$ nulo (Lajes-Reiquiavique $=0 \mathrm{hPa})$, traduzido por uma vasta depressão, com $980 \mathrm{hPa}$ no centro (à superfície), centrada a Oeste da Irlanda, abrangendo grande parte do Atlântico Norte e estendendo a sua influência à Europa Ocidental e Península Ibérica, sob a forma de uma corrente perturbada de Oeste, em regi- me de circulação, em altitude (geopotencial a $500 \mathrm{hPa}$ ), de carácter zonal. 0 jet stream, na alta troposfera $(300 \mathrm{hPa})$, apresenta as maiores velocidades, de 230 $240 \mathrm{Km} / \mathrm{h}$, entre os $35^{\circ}$ e os $40^{\circ}$ de latitude Norte, sobre os Açores.

Doze horas depois, às $00 \mathrm{~h}$ do dia 15 (fig. 2B), a amplificação de uma ondulação ciclónica do fluxo em altitude (geopotencial a $500 \mathrm{hPa}$ ) gera uma onda baroclínica entre os Açores e a Península Ibérica que, em função do forte dinamismo do ar polar (de origem gronelandesa) no flanco ocidental do vale, e da intensificação da convergência nos níveis baixos e médios da troposfera do flanco oriental do vale (por aumento da vorticidade ciclónica), desencadeia um processo de forte ciclogénese no Atlântico a Oeste de Portugal Continental. Esta ciclogénese traduz-se, à superfície, no aparecimento de um núcleo secundário, com $990 \mathrm{hPa}$ no centro, no flanco meridional da depressão principal que continua a localizar-se a Oeste da Irlanda. A descida de pressão atmosférica na área dos Açores, em contraste com uma ligeira subida 


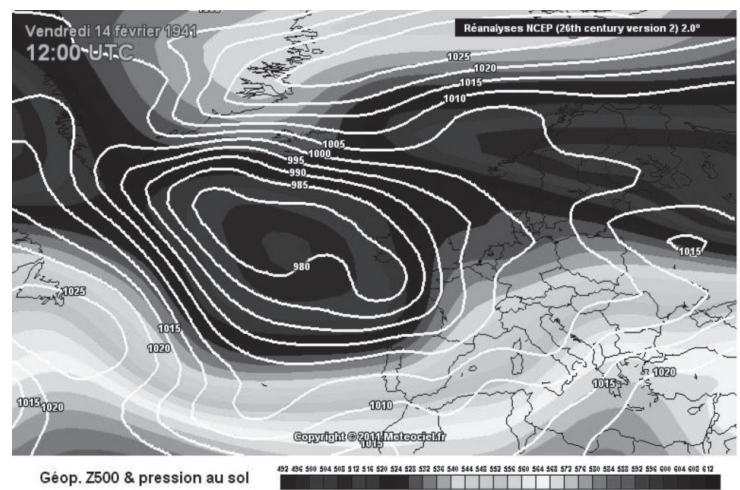

A

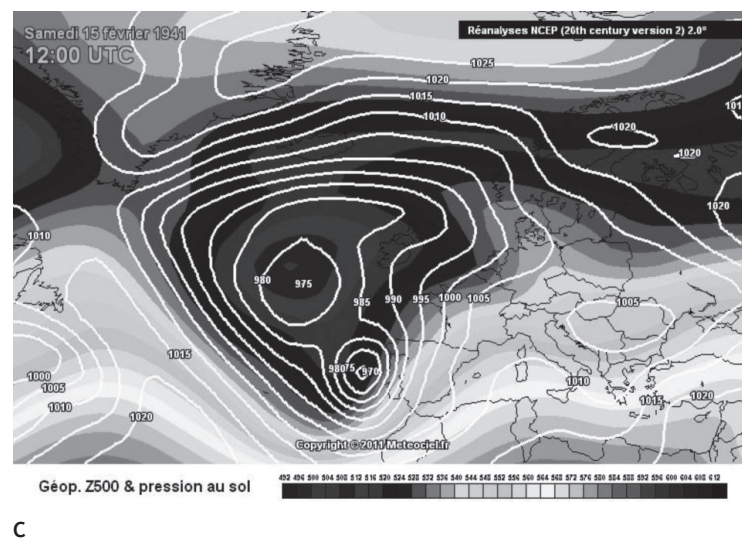

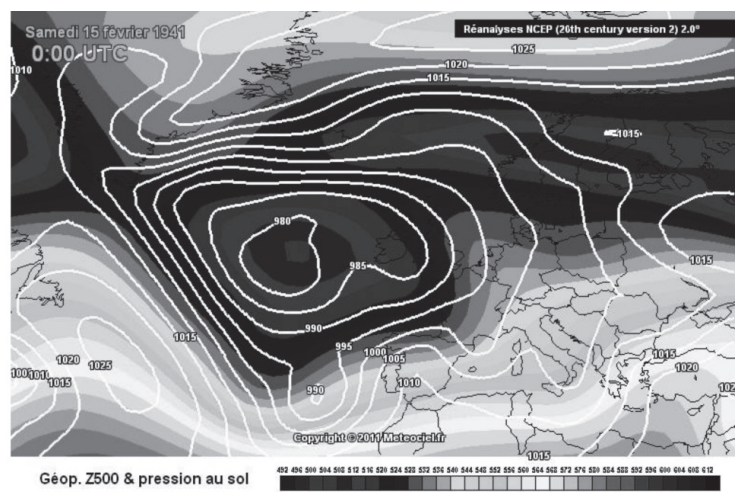

B

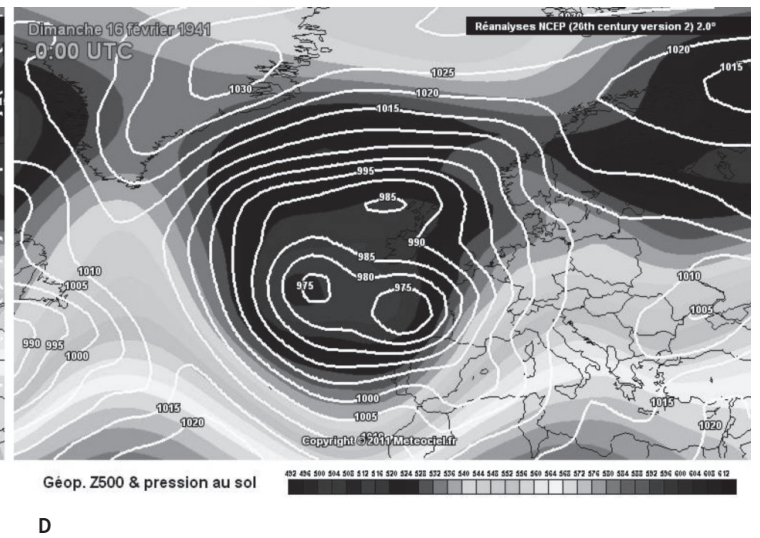

Figura 2

Evolução da situação sinóptica à superfície $(\mathrm{nmm})$ e na média troposfera (geopotencial a 500hPa), das 12h UTC de 14-2-1941 às 00h UTC de 16-2-1941. Fonte: www.meteociel.fr

barométrica na Islândia, impõe à NAO um índice negativo (Lajes-Reiquiavique $=-10 \mathrm{hPa}$ ). A ondulação do jet stream em altitude, com velocidades máximas de $240-250 \mathrm{Km} / \mathrm{h}$ a $300 \mathrm{hPa}$ no flanco ocidental da onda baroclínica, marcando o contorno do ar polar, evidencia, a par da ciclogénese, uma intensa frontogénese fria.

Ao início da tarde (12h UTC) do dia 15 (Fig. 2C), não obstante o índice da NAO não se ter alterado nas últimas doze horas, mantendo o mesmo valor (LajesReiquiavique $=-10 \mathrm{hPa}$ ), durante este período verificase um aumento da amplitude da ondulação do fluxo em altitude (geopotencial a $500 \mathrm{hPa}$ ), intensificando fortemente a convergência sobre Portugal Continental e Atlântico adjacente e, consequentemente, a ciclogénese, que assume características de ciclogénese explosiva. Por definição, uma situação de ciclogénese é denominada de explosiva quando a pressão atmosférica desce, pelo menos, $1 \mathrm{hPa}$ por hora durante um período de 24 horas (para a latitude de $60^{\circ}$, podendo o valor da descida de pressão ser ligeiramente menor para $40^{\circ}$ de latitude). Ora, o aprofundamento do núcleo depressionário entre os Açores e a Península Ibérica, ao longo do seu percurso de aproximação à costa ocidental portuguesa, entre as $12 \mathrm{~h}$ UTC do dia 14 e as $12 \mathrm{~h}$ UTC do dia 15 de Fevereiro de 1941 , foi de $35 \mathrm{hPa}$ em $24 \mathrm{~h}$, o que traduz claramente o seu carácter explosivo e acompanhado pelo cavamento rápido da depressão, com a consequente intensificação da velocidade do fluxo nos níveis baixos da troposfera, especialmente no flanco oriental da perturbação. As tempestuosas velocidades do vento observadas, à superfície, em inúmeras estações meteorológicas do território de Portugal Continental (e também no Norte de Espanha), são decorrentes da conjugação de forte actividade ciclogénica, com a aproximação e passagem (após as 12h UTC) de uma superfície frontal fria muito activa, sobreposta por um tramo do jet stream com velocidades superiores a $200 \mathrm{Km} / \mathrm{h}$ nos níveis altos da troposfera. 
Ao longo da tarde do dia 15, o centro da perturbação frontal, no seu percurso para Nordeste e ainda em fase de cavamento, localiza-se às $18 \mathrm{~h}$ UTC sobre o Noroeste de Portugal e Galiza, com uma pressão atmosférica, à superfície, estimada em $960 \mathrm{hPa}$, segundo RUBIO (2001, citando MATEO GONZÁLES, 1955), que refere ainda que, no seu trajeto entre a Galiza e a costa asturiana, a pressão no centro da depressão terá chegado a $950 \mathrm{hPa}$. Porém, às 00h UTC do dia 16 de Fevereiro (Fig. 2D), decorridas apenas algumas horas, e em fase de rápido enchimento, o centro da perturbação localiza-se já próximo da Bretanha, significativamente menos profunda (975hPa à superfície) e cavada, fazendo parte integrante de uma vasta depressão complexa atlântica, situação normal e frequente nesta altura do ano a estas latitudes.

\section{Efeitos a nível nacional}

Numa breve síntese aos danos causados, a nível nacional, destaca-se o elevado número de vítimas mortais, superior a uma centena, e o número indefinido de feridos ${ }^{2}$. Muitas das vítimas mortais, em especial, em Lisboa, Alhandra, Sesimbra, Alhos Vedros terão sido por afogamento devido a inundações que ocorreram nas áreas ribeirinha. Estas inundações terão resultado da conjugação de múltiplos fatores, destacando-se, entre eles, a sobreelevação do nível do mar ou "storm surge". Esta sobreelevação referese à subida temporária do nível do mar resultante da existência de condições meteorológicas anómalas, nomeadamente de variações no campo da pressão atmosférica e/ou da ação de ventos fortes e prolongados (TABORADA e DiAs, 1992).

Teoricamente, a descida de um milibar (um hectopascal) na pressão atmosférica provoca uma subida de $10 \mathrm{~mm}$ no nível marinho (APRH, 2012). Por outro lado, a força tangencial sobre a superfície marinha dos fortes ventos registados terão provocado um transporte de massa, do que resulta, com frequência, um excesso de água junto à costa (empilhamento) e, consequente, sobreelevação do nível marinho. Daí que alguns jornais se referissem à forte ondulação registada em todo o litoral Português, falando mesmo em ondas com 20 m, no Terreiro do Paço.

${ }^{2}$ De uma análise aos jornais da época, surgem alguns números que poderão constituir mera indicação dos perecimentos ocorridos a nível nacional. Em Lisboa terão rondado as duas dezenas; em Alhandra terão sido 25; em Aveiro 12, em Setúbal 8, em Portalegre 4; na Guarda 2; em Castelo Branco 1; em Évora 3, em Coimbra 3; em Leiria 1; em Alcácer do Sal 8; em Abrantes 4; em Torres Novas 3; em Alhos Vedros 2; em Sesimbra 4, e na Serra da Estrela 1 (...).
Além das vítimas mortais, foram avultados os danos nas telecomunicações e em outras infra-estruturas. As comunicações telegráficas e telefónicas com a Capital ficaram interrompidas durante vários dias, tendo sido restabelecidas com algumas áreas do território apenas no dia 20 de Fevereiro. Também se assinalaram vários cortes nos caminhos-de-ferro, motivados por acidentes, alguns dos quais com vítimas mortais (ex. Lamarosa/Coimbra: choque de comboios com 2 vitimas mortais; entre Travagem e Leandro/Minho, devido à queda de uma árvore, 3 mortes). A rede viária foi, também, afetada principalmente devido à queda de árvores.

São, também, referidos cortes no fornecimento de eletricidade e graves prejuízos em fábricas, habitações e monumentos. Por exemplo em Lisboa, refere-se a destruição da muralha marginal desde Alcântara até à Torre de Belém e em Coimbra salientam-se os graves danos no Hospital da Universidade.

Centenas de embarcações ter-se-ão afundado ou ficado com graves danos, destacando-se o caso de Sesimbra em cujos jornais referem o afundamento de mais de 3 centenas enquanto as danificadas ascendem às 6 centenas. No estuário do Tejo é referido o afundamento de mais de 150 embarcações.

Os estragos ao nível da floresta terão sido muito avultados. Centenas de milhares de árvores foram completamente arrancadas ou então ficaram com graves danos. No Pinhal de Leiria terão sido mais de $\mathbf{3 0 0}$ mil as árvores afetadas; em Abrantes referem-se mais de 200 000 pés, em Nisa o total de árvores danificadas ascenderia a 375000, em Évora é referida a destruição de 10 mil eucaliptos e 20 mil pinheiros na Mata Nacional de Virtudes. No município de Seia, a pequena freguesia de Cabeça refere a destruição de 15500 pinheiros, mais de 500 oliveiras e cerca de 150 árvores de fruto.

Em súmula, a avaliação dos danos causados pelo ciclone de 1941 terão ascendido a 1 milhão de contos, o que representava na altura metade do orçamento nacional. Fazendo a atualização para os dias de hoje e contabilizando os prejuízos causados na altura, esta tempestade orçaria em cerca de 5 mil milhões (MuIRWood, 2011).

\section{Efeitos no município de Coimbra}

A avaliação dos estragos em Coimbra, tendo por base a "Relação dos prejuízos e danos sofridos por particulares nas freguesias do concelho de Coimbra, por ocasião do ciclone de 15 de Fevereiro de 1941", perfez uma quantia superior a 5600 contos, resultando esse valor da avaliação dos estragos em casas e outros bens 
construídos e, sobretudo, dos danos causados nas diversas espécies arbóreas ${ }^{3}$ (Figura 3). De facto, foi enorme a devastação causada no arvoredo do município, tendo sido afetados cerca 230000 pés. Entre as espécies mais dizimadas salienta-se o pinheiro bravo, espécie dominante na floresta em Portugal, seguido da oliveira, que desempenhava uma importante função na economia doméstica, assente na exploração de atividades agroflorestais (Figura 4).

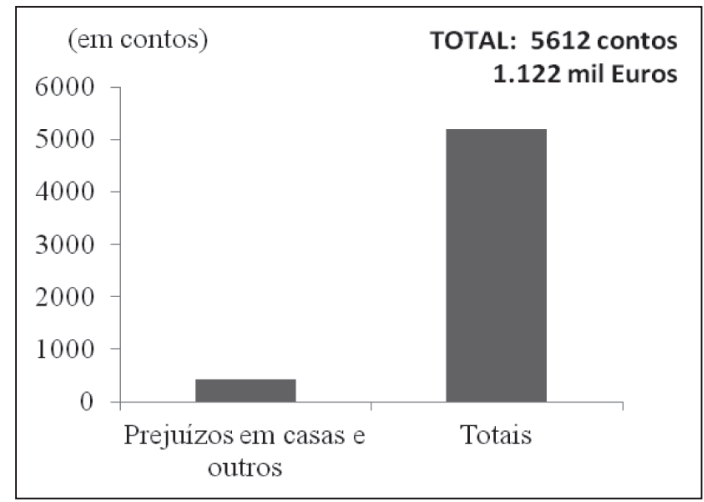

Figura 3

Prejuízos totais em bens particulares

Contudo, a espacialização dos danos totais inventariados mostra que nem todas as freguesias do município foram afetadas com a mesma intensidade (Figura 5). Algumas, em particular, as do centro urbano ( $S$. Cruz, Almedina, S. Bartolomeu e Sé Nova) parecem ter sido poupadas no que toca aos efeitos deste temporal nos bens particulares. Em contrapartida, as do limite ocidental (Lamarosa, S. Silvestre, Ameal e Taveiro) e meridional (Almalaguês, Castelo Viegas e Assafarge), a que se juntam as de Botão e Torres de Mondego, foram as mais dizimadas quer pelos estragos nos bens particulares construídos quer pelas perdas em termos de coberto florestal. De salientar, que não fazem parte desta contagem os bens eclesiásticos, do Estado ou até do município. A título de exemplo, salientam-se os prejuízos e danos, no valor de algumas centenas de contos, sofridos na Mata do Choupal e no Parque de Santa Cruz, o primeiro da Câmara Municipal e o segundo do Estado, onde caíram muitas árvores, algumas de elevado valor estimativo.

${ }^{3}$ De acordo com a referida relação de prejuízos o valor a requerer por cada uma das espécies arbóreas danificadas era o seguinte: Oliveiras: $80 \$ 00$; Pinheiros: $7 \$ 00$; Eucaliptos: $20 \$ 00$; Figueiras: $15 \$ 00$; Pereiras: 30\$00; Pessegueiros: $30 \$ 00$; Nogueiras: $40 \$ 00$; Macieiras: 30\$00; Nespereiras: 25\$00; Ameixieiras: $20 \$ 00$.

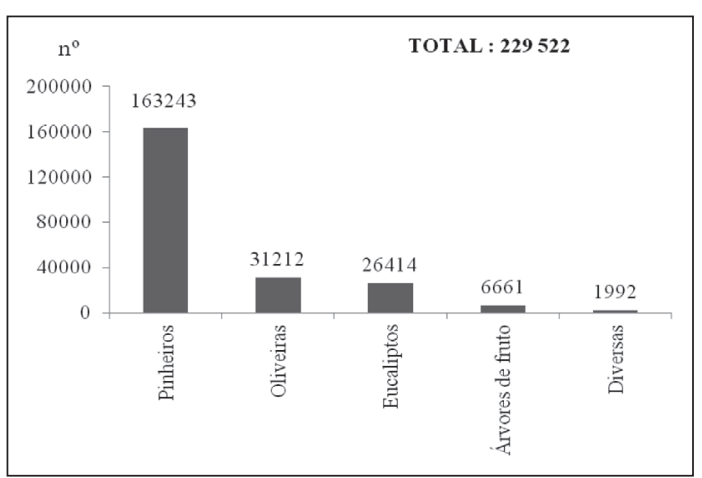

Figura 4

Árvores danificadas por espécie

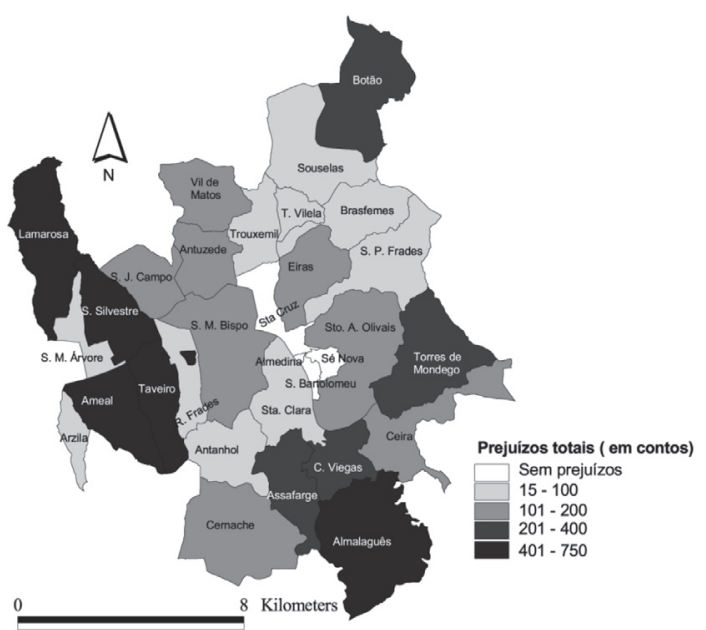

Figura 5

Prejuízos totais em bens particulares, por freguesia

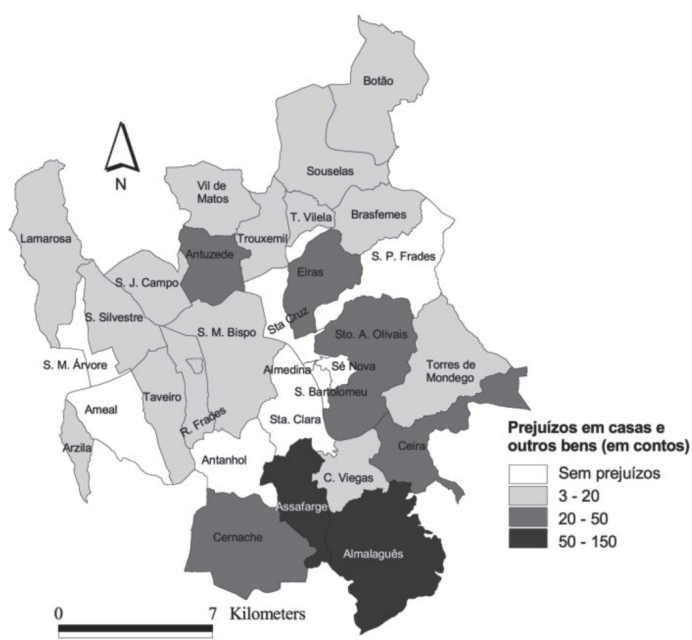

Figura 6

Prejuízos totais em casas e outros bens, por freguesia 
A distribuição espacial dos prejuízos em casas de habitação e outros bens construídos (muros, moinhos...) aparece representado no mapa da Figura 6. Almalaguês e Assafarge surgem com os maiores prejuízos, referindo o relatório, proveniente da primeira Junta de Freguesia, que «... todas as casas sofreram prejuízos nos telhados, e algumas também nas paredes e janelas. Algumas famílias ficaram em circunstâncias muito precárias». Em Antuzede referem-se danos em 19 casas, sobretudo devido ao seu destelhamento, e num moinho de vento. Já em Botão, foram 115 o número de moradores com prejuízos em casas, enquanto em Souselas terão sido 20 os lesados.

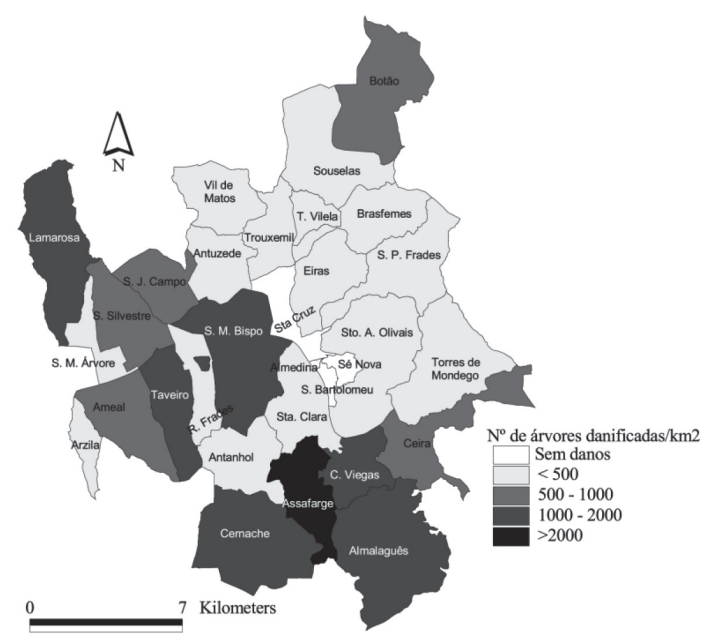

Figura 7

$\mathrm{N}^{\circ}$ de árvores danificadas por $\mathrm{km}^{2} /$ freguesia

No que se refere às freguesias mais afectadas em termos de árvores, sobressai Assafarge, com mais de 2000 pés, arrancados ou danificados, por $\mathrm{Km}^{2}$. Seguem-se de Almalaguês, Castelo Viegas, Cernache, S. Martinho do Bispo, Taveiro e Lamarosa. Esta maior devastação em termos de coberto arbóreo pode relacionar-se com a maior densidade de arvoredo mas também pela preponderância de ventos de quadrante Sul, os quais poderão ter tido, nestas áreas, um potencial destrutivo acentuado pela interação dos fluxos com o relevo regional.

\section{Exposição e vulnerabilidade à época vs atualidade}

De acordo com a United Nations (2009) exposição refere-se às pessoas, bens, sistemas ou outros elementos presentes nas áreas de risco que poderão ser objeto de potenciais perdas, enquanto a vulnerabilidade se relaciona com o grau de perda de um elemento ou con- junto de elementos vulneráveis, resultante da ocorrência de um fenómeno (natural ou induzido pelo Homem) com determinada magnitude ou intensidade.

Justifica-se, por conseguinte, uma breve reflexão sobre a exposição e a vulnerabilidade à época e os potenciais efeitos da manifestação deste tipo de evento extremo na atualidade. Com efeito, no que se refere à população exposta à manifestação deste risco, seria em número significativamente inferior uma vez que desde 1940 até ao último recenseamento da população, de 2011, se assinalou um incremento de 36\% (Quadro I).

Quadro I

Breve reflexão sobre a exposição e a vulnerabilidade à época e os potenciais efeitos da manifestação deste tipo de episódio na atualidade. Síntese das alterações

\begin{tabular}{|c|c|c|c|}
\hline & 1940 & 2011 & $1940-2011$ \\
\hline $\begin{array}{l}\begin{array}{l}\text { População total } \\
\text { (hab.) }\end{array} \\
\text { Fonte: INE } \\
\end{array}$ & 7722152 & 10561614 & > exposição \\
\hline $\begin{array}{l}\mathrm{N}^{\circ} \text { de alojamentos } \\
\text { Fonte: INE }\end{array}$ & 2118033 & 5520681 & > exposição \\
\hline $\begin{array}{l}\text { Arquitetura e novos } \\
\text { materiais de } \\
\text { construção }\end{array}$ & & & > vulnerabilidade \\
\hline Rede elétrica & & & > vulnerabilidade \\
\hline $\begin{array}{l}\text { Rede de estradas } \\
(\mathrm{km})\end{array}$ & 16900 & $\begin{array}{c}90000 \text { (est. } \\
\text { Municipais) } \\
13100(\mathrm{AE}, \mathrm{IP}, \\
\text { IC e estradas } \\
\text { regionais) }\end{array}$ & $\begin{array}{c}\text { >exposição } \\
\text { > vulnerabilidade }\end{array}$ \\
\hline $\begin{array}{l}N^{\circ} \text { de automóveis } \\
\text { Fonte: ACAP }\end{array}$ & $\begin{array}{l}\text { 1/149 hab. } \\
\text { (54 } 700 \text { aut.) }\end{array}$ & $\begin{array}{l}1 / 1,8 \text { hab. } \\
\text { (5 } 727100 \\
\text { aut.) }\end{array}$ & $\begin{array}{c}\text { > exposição } \\
\text { > vulnerabilidade }\end{array}$ \\
\hline
\end{tabular}

O mesmo acontece quando se analisa a evolução dos alojamentos, os quais mais do que duplicaram nestas últimas 7 décadas, embora se possa considerar que a respetiva vulnerabilidade seja inferior face à manifestação de um fenómeno meteorológico com características idênticas, sobretudo pela melhoria assinalada na qualidade das construções. Todavia, a arquitetura de alguns edifícios, muitos dos quais em altura, associados a novos materiais de construção (mais leves e de maior dimensão) aumenta o efeito mecânico do vento sobre os mesmos, incrementando, assim, a sua vulnerabilidade. Basta pensarmos, nos impactes dos fortes ventos registados recentemente no Algarve e nos danos que causaram no aeroporto de Faro.

Relativamente à rede elétrica, pouco extensa em 1940, foi na altura fortemente afetada. Aliás é só a partir de 1944 que se verifica uma política efetiva de eletrificação nacional, portanto, na atualidade os danos seriam bastante severos, tendo como exemplo a tempestade de vento que ocorreu na região Oeste, em Dezembro de 2009. 
A rede de estradas foi, de igual modo, fortemente ampliada. A rede municipal expandiu-se significativamente e com a rede de auto-estradas, IP, IC e estadas regionais, não só aumentou a exposição à queda de árvores, como também se assinala uma maior vulnerabilidade à ocorrência de acidentes de viação, sobretudo nestas últimas vias, pela maior velocidade de circulação que permitem, e também pelo efeito mecânico da variabilidade espacial da velocidade do vento imposta pelos fatores geográficos.

Por outro lado, não se poderá esquecer o brutal aumento do parque automóvel, hoje com mais de $5 \mathrm{mi}$ lhões de viaturas contra os pouco mais de 50000 automóveis em 1940, o que se traduz num incremento da sua exposição e vulnerabilidade à queda de árvores, muros, mas também à ocorrência de acidentes de viação.

\section{Conclusão}

Este evento meteorológico extremo, por ter ocorrido numa época de escassez de informação sinóptica, não terá sido investigado de acordo com a importância que os seus efeitos exigiriam no sentido de mitigar os impactes da sua recorrência. De facto, a pertinência da sua análise, quer em termos de causas sinóticas quer em termos de impactes no território português, reforça-se se tivermos em conta que estes episódios extremos têm vindo a aumentar, nestas últimas décadas (Centre for the Research on the Epidemiology for Disasters, CRED) e terão tendência a incrementar-se com o aquecimento global (Lopes e Fragoso, 2010).

Acresce, por outro lado, o facto dos riscos associados a ventos fortes terem sido pouco considerados no ordenamento do território. Reforça-se, neste contexto, a necessidade de apostar na elaboração de cartografia de ventos potencialmente fortes, à escala regional, aplicada ao ordenamento do território e, à escala local, aplicada aos Planos Directores Municipais e aos Planos de Urbanização.

Naquele dia de Fevereiro $O$ vento estava a nascente Não ficou nenhum pinheiro Levou tudo pela frente.

Foi no ano de quarenta e um

Que tudo isto aconteceu Não ficou telhado algum

Onde o vento não mexeu.
Era um ciclone, um tufão Vento e chuva, um vendaval Deitou as árvores ao chão

Nos telhados foi fatal

As lousas da cobertura

Pareciam papéis no ar

Caíam na calçada dura

Pareciam bombas a estalar.

DIAS, José (2007) - "Histórias e Lendas da Minha Aldeia- Cabeça", Ciclone de 1941, p. 175, Gouveia.

\section{Bibliografia}

APRH (2012) - "Glossário das Zonas Costeiras". Gestão Costeira Integrada (disponível em http://www.aprh.pt/rgci/ glossario/sobreelevacaomar.html, 04-06-2012).

DIAS, José (2007) - "Histórias e Lendas da Minha Aldeia- Cabeça", O Ciclone de 1941, p. 175, Gouveia.

UnITED Nations (2009) - "UNISDR Terminology on Disaster Risk Reduction". United Nations International Strategy for Disaster Reduction, Geneve, Switzerland.

Lopes, A. e Fragoso, M. (2010) - "A tempestade de 23 de Dezembro de 2009: causas meteorológicas e impactos na região Oeste". II Congresso Internacional e VI Encontro Nacional de Riscos, 23 a 25 de Maio (disponível em http://www. nicif.pt/riscos/congresso/II_Riscos, 04-06-2012)

Mateo González, P. (1955) - El clima de Gijón (Costa Cantábrica de España). SMN.

MuIR-Wood, R. (2011) - "RMS Risk Management Solutions". Trébol, 56, Londres, 10p.

Oliveira, S. e Lopes, A. (2007) - "Metodologia de avaliação do risco de queda de árvores devido a ventos fortes. 0 caso de Lisboa". VI Congresso da Geografia Portuguesa, Lisboa, 17-20 de Outubro, 21 p.

RuBı, J. M. V. (2001) - "Los temporales de viento en la Península Ibérica. Análisis meteorológico de la extraordinaria situación atmosférica de Febrero de 1941". Gerencia de Riesgos y Seguros (Fundación MAPFRE), 74 ( $2^{\circ}$ trimestre de 2001), pp. 29-44.

TABORDA, R. e DiAS, J. A. (1992) - "Análise da Sobreelevação do Mar de Origem Meteorológica durante os Temporais de Fevereiro/Março de 1978 e Dezembro de 1981ם. Geonovas, № Especial 1 "A Geologia e o Ambiente", Lisboa, p.89-97. 